\title{
The effect of a dietary supplement of potassium chloride or potassium citrate on blood pressure in predominantly normotensive volunteers
}

\author{
Alessandro Braschi and Donald J. Naismith* \\ Department of Nutrition and Dietetics, King's College London, Franklin-Wilkins Building, 150 Stamford Street, \\ London SE1 9NN, UK
}

(Received 12 May 2007 - Revised 9 October 2007 - Accepted 11 October 2007 - First published online 6 December 2007)

Blood pressure (BP) shows a continuous relationship with the risk of CVD. There is substantial evidence that dietary potassium exerts an antipressor effect. Most clinical trials have used $\mathrm{KCl}$. However, the chloride ion may have a pressor effect and in foods potassium is associated with organic anions. In a double-blind randomized placebo-controlled trial we explored the effect on $\mathrm{BP}$ of two salts of potassium, $\mathrm{KCl}$ and potassium citrate (K-cit), in predominantly young healthy normotensive volunteers. The primary outcome was the change in mean arterial pressure as measured in a clinic setting. After 6 weeks of supplementation, compared with the placebo group $(n 31), 30 \mathrm{mmol} \mathrm{K}$-cit/d $(n 28)$ changed mean arterial pressure by $-5.22 \mathrm{mmHg}(95 \% \mathrm{CI}-8.85,-4.53)$ which did not differ significantly from that induced by $\mathrm{KCl}(n 26),-4.70 \mathrm{mmHg}$ $(-6.56,-2.84)$. The changes in systolic and diastolic BP were $-6.69(95 \% \mathrm{CI}-8.85,-4.43)$ and $-4.26(95 \% \mathrm{CI}-6.31,-2 \cdot 21) \mathrm{mmHg}$ with $\mathrm{K}$-cit and $-5.24(95 \% \mathrm{CI}-7.43,-3.06)$ and $-4.30(95 \% \mathrm{CI}-6.39,-2.20) \mathrm{mmHg}$ with $\mathrm{KCl}$, and did not differ significantly between the two treatments. Changes in BP were not related to baseline urinary electrolytes. A greater treatment-related effect was observed in those with higher systolic BP. Increasing dietary potassium could therefore have a significant impact on the progressive rise in BP in the entire population.

Blood pressure: Dietary supplementation: Potassium salts: Clinical trials: Human subjects

Elevated blood pressure (BP) is the most common risk factor for cardiovascular mortality and morbidity worldwide ${ }^{(1)}$. Much attention has been given to the role of diet in influencing $\mathrm{BP}$, in particular to the pressor effect of sodium ${ }^{(2)}$ and more recently to the anti-pressor effect of potassium ${ }^{(3,4)}$ and to the interaction between these two cations ${ }^{(5)}$. Diets rich in fruits and vegetables have been found to exert an anti-pressor effect ${ }^{(6-8)}$ which has been attributed in part to their high content of potassium ${ }^{(4,5,7)}$. Most clinical trials on potassium and BP have been performed on a small sample of hypertensive subjects, having an intervention period lasting less than 1 month and using high doses of $\mathrm{KCl}(60-200 \mathrm{mmol} / \mathrm{d})^{(9,10)}$. However, there is some evidence that the accompanying chloride anion is essential in determining the pressor effect of sodium chloride, as sodium salts of bicarbonate, citrate and phosphate have been found to be ineffective in raising $\mathrm{BP}^{(11)}$. Moreover, potassium in plant foods is present in association with organic anions such as citrate or malate ${ }^{(12)}$ and it has been suggested that chloride per se might have a pressor effect ${ }^{(13)}$. The few studies reported using non-chloride salts of potassium have provided conflicting results.

We hypothesized that organic salts of potassium lower BP and would exert a greater anti-pressor effect than $\mathrm{KCl}$. We therefore conducted a placebo-controlled randomized double-blind trial on healthy volunteers, over a 6-week period, to compare the effect of either $\mathrm{KCl}$ or potassium citrate (K-cit) with a dose $(30 \mathrm{mmol} / \mathrm{d})$ approximating the current dietary deficit in the UK population.

\section{Experimental methods}

Design of the trial

The study, approved by the King's College Research Ethics Committee, took the form of an 8-week randomized, doubleblind placebo-controlled trial with parallel arm design of oral potassium supplementation (ISRCTN no. 52748737). It was aimed to test the effect on BP of $30 \mathrm{mmol} / \mathrm{d}$ of two potassium supplements, $\mathrm{KCl}$ and $\mathrm{K}$-cit, and to evaluate the possible influence of the accompanying anion. The betweengroups difference in increments in mean arterial pressure (MAP), as measured by the oscillometric sphygmomanometer, was the primary outcome.

Based on data from our previous study ${ }^{(14)}$ and assuming a standard deviation of $5.3 \mathrm{mmHg}$ for MAP, a sample size of thirty-five subjects per group was required in order to detect a change in clinic MAP of $4.0 \mathrm{mmHg}$ at $P<0.05$ and $80 \%$ power. A greater number of participants was recruited to allow for dropouts.

Abbreviations: BP, blood pressure; DBP, diastolic blood pressure; K-cit, potassium citrate; MAP, mean arterial pressure; RBC-K, erythrocyte content of potassium; SBP, systolic blood pressure.

* Corresponding author: Professor Donald J. Naismith, fax + 44207333 4285, email djnaismith@ googlemail.com 
Volunteers were invited to participate in a 2-week run-in period during which placebo capsules were taken in order to test adherence or intolerance to the placebo (lactose). They were also asked, on a voluntary basis, to provide a blood and a $24 \mathrm{~h}$ urine sample to obtain baseline values for $24 \mathrm{~h}$ electrolyte excretion, plasma electrolytes and erythrocyte potassium content (RBC-K). Baseline values for BMI, heart rate and $\mathrm{BP}$ were then measured. Volunteers were randomly allocated to receive either a placebo, $\mathrm{KCl}$ or $\mathrm{K}$-cit capsules for 6 weeks and were required to attend a final evaluation during which heart rate, $\mathrm{BP}$ and $\mathrm{BMI}$ were again measured and criteria for exclusion considered. At a mid-term visit BP was again measured after 3 weeks of treatment. Three days from the end of supplementation a second $24 \mathrm{~h}$ urine and blood sample were obtained. Volunteers were asked to complete a questionnaire to determine whether the supplements had side-effects.

Adherence to the treatment was calculated as a percentage of assigned capsules actually consumed and confirmed by urine analysis.

Randomization was performed by a statistician consultant unrelated to the intended study using a series of computer-generated random numbers (Excel, Office 1997, Microsoft Ltd, Reading, UK). Details of the series were unknown to the investigators and were provided on completion of the study.

\section{Subjects}

A total of 127 subjects were recruited from amongst the academic staff and the student population of King's College London. Ninety completed the study.

Participants had to be aged between 22 and 65 years, have a BMI between 19 and $35 \mathrm{~kg} / \mathrm{m}^{2}$, an alcohol consumption of $\leq 21$ units/week for women and $\leq 28$ units/week for men ( 1 unit $=10 \mathrm{ml}$ of ethanol), and have a systolic BP $(\mathrm{SBP}) \leq 160$ and diastolic $\mathrm{BP}(\mathrm{DBP}) \leq 105 \mathrm{mmHg}$ at screening. Subjects taking medications for which potassium supplementation is not contraindicated, or mineral and vitamin supplements, took part with the provision that they would continue their use. None contained potassium. Participants suffering from postural hypotension were also not included.

Subjects suffering from CVD (including cardiac arrhythmia), renal diseases, diabetes, metabolic acidosis and digestive problems or those taking anti-hypertensive medications, cyclosporin, heparin, digoxin, anticholinergics and non-steroidal anti-inflammatory drugs did not participate.

Subjects who during the study period changed either their usual diet or lifestyle and those undergoing changes in psychical condition (stress, depression, tiredness) were excluded. Volunteers who during the run-in consumed less than $80 \%$ of the placebo would not proceed to the supplementation phase, while data from those who consumed less than $70 \%$ during the intervention would be rejected.

\section{Treatment administered}

The supplements of potassium and the placebo were formulated at Penn Pharmaceutical Services Ltd (Tredegar, UK). The supplement contained $5 \mathrm{mmol}$ potassium microencapsulated with Eudragit NE 30 D. The purpose was to obtain a formulation that would gradually release the potassium salts thus avoiding high local concentrations of the salt. Two capsules were taken three times a day after each main meal (breakfast, lunch and dinner).

\section{Blood pressure and heart rate}

BP was measured following current recommendations ${ }^{(15,16)}$ as outlined in our previous study ${ }^{(14)}$. Briefly, BP was assessed at approximately the same time of the day (within $30 \mathrm{~min}$ ) by the same observer using the same instruments throughout the study. Participants were asked to maintain the same habits before each appointment, in particular with regard to factors known to influence $\mathrm{BP}^{(15)}$ such as exercise, awakening time and meal time. They were asked to refrain from smoking, eating, drinking and exercising $30 \mathrm{~min}$ before each appointment. Those who felt unwell or stressed, or had changes of pulse greater than 15 beats/min when compared with the average baseline pulse were asked to arrange another appointment.

BP was measured in the seated position in the left arm after a $10 \mathrm{~min}$ rest using a clinically validated ${ }^{(17)}$ semi-automated oscillometric sphygmomanometer (UA-779; A \& D Instruments Ltd, Maidenhead, UK) providing pulse measurements. Three readings were taken at $2 \mathrm{~min}$ intervals. The values for SBP were then averaged, the reading that had the greatest difference from the mean being discarded together with the corresponding DBP and pulse measurement, and the mean of the two remaining readings used for analysis.

BP was thereafter confirmed by taking two more readings at 2 min intervals with a validated ${ }^{(18)}$ mercury sphygmomanometer (Trimline-PyMah; MedRoDi Medical Ltd, Whitecross, UK). SBP was measured as the point of appearance of the Korotkoff sounds (Phase I) while DBP was judged as the point of complete disappearance of the sounds (Phase V).

MAP was calculated as $(2 \mathrm{DBP}+\mathrm{SBP}) / 3$. Three different cuffs were used depending on arm circumference ${ }^{(15)}$. Participants with measurements of either SBP $\geq 140$ or DBP $\geq 90$ $\mathrm{mmHg}$ were regarded as hypertensive ${ }^{(19)}$. Since oscillometric monitors may be unreliable for some individuals for which there is no obvious reason ${ }^{(20)}$, those who at screening had a discrepancy for BP between the mercury and oscillometric device $\geq 9 \mathrm{mmHg}$ for $\mathrm{SBP}$ or $\geq 5 \mathrm{mmHg}$ for $\mathrm{DBP}^{(17)}$ were deemed unsuitable for oscillometric instruments.

\section{Erythrocyte potassium and water content}

Fasting venous blood samples were drawn into $10 \mathrm{ml}$ lithium heparin tubes kept at room temperature and processed within $1 \mathrm{~h}$. An aliquot of $0.5 \mathrm{ml}$ was centrifuged (Ames Microspin, Bayer Diagnostic GmbH, Germany) for haematocrit determination.

To assess erythrocyte potassium content a modification of the method devised by Weissberg et al. ${ }^{(21)}$ relating the electrolyte content of an erythrocyte lysate to its dry mass was used. Blood was centrifuged at $3000 \mathrm{~g}$ for $5 \mathrm{~min}$ at $4^{\circ} \mathrm{C}$, the buffy coat discarded and plasma kept for analysis. The erythrocytes were washed four times with $5 \mathrm{ml}$ isosmolar $110 \mathrm{mmol} / 1 \mathrm{MgCl}_{2}$, spinning for $3 \mathrm{~min}$ at $3000 \mathrm{~g}$ at $4^{\circ} \mathrm{C}$ and discarding the supernatant. Approximately $1 \mathrm{ml}$ of washed cells was lysed in $4 \mathrm{ml}$ of ultrapure water. Then $1 \mathrm{ml}$ of lysate was accurately pipetted and dried at $60^{\circ} \mathrm{C}$ to constant 
weight. The remaining $3 \mathrm{ml}$ of lysate was centrifuged at $3000 \mathrm{~g}$ for $3 \mathrm{~min}$, and a duplicate aliquot of $1 \mathrm{ml}$ was stored for analysis. After chemical analysis the intra-assay $\mathrm{CV}$ on five estimates was $<3 \%$.

Erythrocyte water content was estimated as the percentage (w/w) of weight lost from a duplicate sample of washed packed cells $(\sim 0.25 \mathrm{ml})$ before and after desiccation ${ }^{(22)}$. This technique gave an intra-assay $\mathrm{CV}$ on five estimates of $<1 \%$.

\section{Laboratory analysis}

Samples of urine, plasma and lysate were stored at $-80^{\circ} \mathrm{C}$. Assays on urine electrolytes and creatinine, plasma electrolytes and the potassium content in the erythrocyte lysate were carried out by the Department of Chemical Pathology at St Thomas' Hospital, London. For analysis for potassium and sodium an automated clinical analyser employing ionselective electrodes (Synchron LX20; Beckman Coulter Ltd, High Wycombe, UK) was used. The sensitivity for both ions was $2 \mathrm{mmol} / \mathrm{l}$. Creatinine concentration was determined using the Jaffe rate method (Synchron LX20) with a precision of $177 \mu \mathrm{mol} / \mathrm{l}$.

\section{Statistical analysis}

The present trial was designed to test the alternative hypothesis that the increments in BP would differ among the three different intervention groups.

All data were checked for normality using the One-sample Kolmogorov-Smirnov test, and all but alcohol consumption and vegetarianism were confirmed to be normally distributed. The $\chi^{2}$ test was used to assess the significance of differences between the groups for nominal-level variables (e.g. gender). For interval-level variables (e.g. BP) the significance of differences between the groups at baseline was tested using ANOVA, while changes after the intervention period were tested using ANOVA with covariates (ANCOVA). When a significant difference was detected the pairwise comparison was made by using the least significant difference technique. For interval-level variables the significance of differences in parameters within each intervention group was tested by the paired sample $t$ test (two-sided). The influence of nominallevel variables on interval-level variables was assessed using either the independent samples $t$ test or alternatively ANOVA for more than two categories. Relationships between interval-level variables were examined using the Pearson correlation test (two-sided), or with the Spearman correlation test (two-sided) when non-normally distributed variables were involved.

Data are presented as means and their standard errors. The increments of the parameters observed after the intervention period are presented as estimated marginal means, standard errors and $95 \%$ CI. A $P$ value of $\leq 0.05$ was considered to be statistically significant.

Sample size and power calculation was estimated using Minitab statistical software (version 13.1; Minitab Ltd, Coventry, UK). All the other calculations were performed with the SPSS statistical software package SPSS 13.0 for Windows (SPSS UK Ltd, Woking, UK).

\section{Results}

\section{Subject details}

A detailed flowchart showing enrolment and allocation of the volunteers into the different intervention groups, and including reasons for withdrawal or exclusion, is presented in Fig. 1. None of the participants were excluded for poor compliance. Inequalities between the number reported for groups and totals arose from exclusions and withdrawals.

The baseline characteristics of the volunteers are shown in Table 1. There were no significant differences among the treatment groups other than for height and BMI that differed significantly between the placebo and the $\mathrm{KCl}$ group. The difference in height reflected the greater, although non-significant, number of females who were allocated to the $\mathrm{KCl}$ group.

\section{Compliance and side-effects}

The compliance as judged by pill counting was 90.0 (SEM 1.5) $\%$ in the placebo group, 91.4 (SEM 1.2) \% in the $\mathrm{KCl}$ group and 92.5 (SEM 1.2) \% in the K-cit group during the intervention period. However, a comparison of urinary potassium excretion between the groups (see later) indicated that compliance was approximately $75 \%$ in the $\mathrm{KCl}$ group and $83 \%$ in the K-cit group.

The capsules were well tolerated, with no clinically significant side-effects.

\section{Blood pressure and heart rate}

At baseline two volunteers in the K-cit group were classified as hypertensives while after 6 weeks of intervention the number was reduced to one. Mean BP was not significantly different among the three groups at baseline and throughout the duration of the study.

Baseline SBP was significantly correlated with baseline body weight $(r 0.47, P=0.000)$, baseline BMI ( $r \quad 0.44$, $P=0.000)$, age $(r 0.28, P=0.010)$ and alcohol consumption ( $r$ 0.24, $P=0.026$ ). Significant correlations were also found between DBP and baseline BMI ( $r$ 0.33, $P=0.002)$, body weight $(r 0 \cdot 26, P=0.018)$ and age $(r 0 \cdot 27, P=0 \cdot 012)$.

At the end of the 6-week intervention period mean BP decreased significantly from baseline within the potassiumsupplemented groups (Fig. 2), while no change was observed in the placebo group. When comparing the changes in BP between the three different groups no significant differences were found between the two potassium treatments while BP changes between the active treatments and the placebo group achieved statistical significance (Table 2). The decrease in BP observed in the potassium groups occurred gradually, with an early decrease in both SBP and DBP followed by a predominant decrease in SBP during the last 3-week period.

In the analysis of covariance no significant relationships were found between the changes in BP and baseline BMI, age, gender, heart rate, urinary electrolyte excretion, plasma electrolytes, erythrocyte water and potassium content. In particular, no significant relationships were found between the changes in BP and the changes in the above variables as covariates. However, a significant relationship $(P=0.007)$ was found between the change in SBP (final from baseline) and SBP level (calculated as the mean of all measurements 


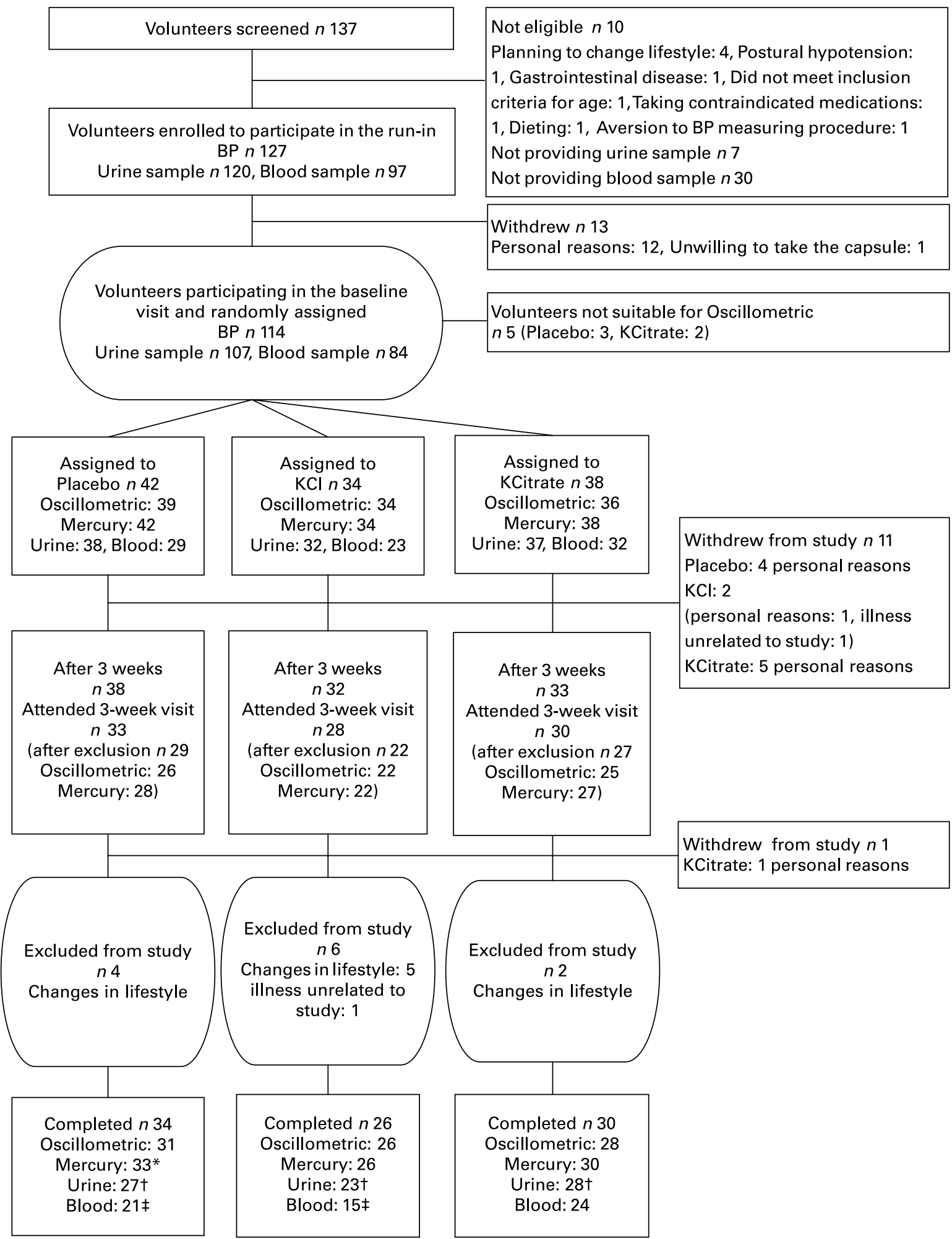

Fig. 1. Flow diagram of enrolment and visit completion of the participants in the study. ${ }^{*}$ One volunteer belonging to the placebo group could not provide reliable blood pressure (BP) readings from the mercury sphygmomanometer at the mid-point and final visits, as the Koroktoff sounds were faint and of difficult interpretation. TOne volunteer in the potassium citrate (KCitrate) and $\mathrm{KCl}$ group and three volunteers in the placebo group could not provide a complete $24 \mathrm{~h}$ urine sample for the final assessment. $¥$ Two volunteers in the placebo group and one in the $\mathrm{KCl}$ group were excluded from erythrocyte potassium content analysis owing to errors made during the preparation of the haemolysates from the final blood samples. For one volunteer in the placebo group the final haematocrit and erythrocyte water content determinations were lost. 
of SBP) as covariate (common slope $=-0 \cdot 111 \pm 0 \cdot 040$, intercept varies according to treatment).

There were no significant differences in mean heart rate at baseline (placebo 67.5 (SEM 1.3); KCl 67.5 (SEM 1.8); K-cit 67.8 (SEM 1.9)). During the intervention period pulse did not change significantly within the three groups, nor did mean changes differ significantly between the groups.

\section{Urinary excretion of electrolytes}

Baseline mean urinary electrolytes and creatinine excretion did not differ significantly between the three treatment groups (Table 3).

At the end of the supplementation period in the potassium groups the mean urinary excretion of potassium increased significantly from baseline. As a result the daily urinary excretion of potassium was significantly greater $(P<0.010)$ in the K-cit $(98.17$ (SEM 5.02) $\mathrm{mmol} / \mathrm{d})$ and $\mathrm{KCl}(89.58$ (SEM 6.96) $\mathrm{mmol} / \mathrm{d}$ ) groups than in the placebo group (66.75 (SEM $5.49 \mathrm{mmol} / \mathrm{d})$ ). Compared with the placebo group urinary potassium increased significantly by 24.98 (SEM 8.47) $\mathrm{mmol} / \mathrm{d}$ (95\% CI 8.12, 41.85; $P<0.010)$ in the $\mathrm{K}$-cit group and by 22.60 (SEM 8.91 ) $\mathrm{mmol} / \mathrm{d}(95 \%$ CI $4.86,40.34 ; P<0.010)$ in the $\mathrm{KCl}$ group. In the $\mathrm{K}$-cit group the mean molar ratio of sodium to potassium $(\mathrm{Na}-\mathrm{K}$ ratio) and the mean creatinine excretion decreased significantly from the respective baseline values, but these changes were not significantly different when compared with the other two groups.

\section{Plasma electrolytes, erythrocyte water and potassium content}

Baseline values for plasma electrolytes were similar among three intervention groups (Table 3). After the 6-week intervention period, there were no significant changes in plasma

Table 1. Baseline characteristics of the participants

(Mean values with their standard errors)

\begin{tabular}{|c|c|c|c|c|c|c|}
\hline & \multicolumn{2}{|c|}{ Placebo ( $n$ 34) } & \multicolumn{2}{|c|}{$\mathrm{KCl}(n 26)$} & \multicolumn{2}{|c|}{ K-cit $(n 30)$} \\
\hline & Mean & SEM & Mean & SEM & Mean & SEM \\
\hline Age (years) & 33.8 & $2 \cdot 2$ & 36.9 & $2 \cdot 8$ & $36 \cdot 2$ & $2 \cdot 6$ \\
\hline$\%$ Female & \multicolumn{2}{|c|}{58.8} & \multicolumn{2}{|c|}{80.8} & \multicolumn{2}{|c|}{$56 \cdot 7$} \\
\hline Height $(\mathrm{m})$ & $1 \cdot 71^{*}$ & 0.01 & 1.65 & 0.02 & 1.70 & 0.02 \\
\hline Weight (kg) & $66 \cdot 1$ & $2 \cdot 2$ & $68 \cdot 7$ & 3.5 & 70.5 & 2.6 \\
\hline BMI $\left(\mathrm{kg} / \mathrm{m}^{2}\right)$ & $22.55^{\star}$ & 0.53 & $25 \cdot 20$ & 1.06 & 24.50 & 0.78 \\
\hline $\begin{array}{c}\text { Physical activity } \\
\text { (h/week) }\end{array}$ & $2 \cdot 0$ & 0.2 & $2 \cdot 4$ & 0.3 & $2 \cdot 6$ & 0.3 \\
\hline $\begin{array}{l}\text { Alcohol intake } \\
\quad \text { (units/week) }\end{array}$ & $7 \cdot 1$ & 1.5 & $6 \cdot 2$ & $1 \cdot 2$ & $7 \cdot 3$ & 1.5 \\
\hline$\%$ Smokers & \multicolumn{2}{|c|}{$17 \cdot 6$} & \multicolumn{2}{|c|}{11.5} & \multicolumn{2}{|c|}{$16 \cdot 7$} \\
\hline $\begin{array}{l}\% \text { Familial } \\
\text { hypertension }\end{array}$ & \multicolumn{2}{|c|}{$44 \cdot 1$} & \multicolumn{2}{|c|}{38.5} & \multicolumn{2}{|c|}{$30 \cdot 0$} \\
\hline $\begin{array}{l}\% \text { Vegetarian } \\
\text { Ethnic origin }\end{array}$ & \multicolumn{2}{|c|}{11.8} & \multicolumn{2}{|c|}{$15 \cdot 4$} & \multicolumn{2}{|c|}{$13 \cdot 3$} \\
\hline$\%$ Caucasian & \multicolumn{2}{|c|}{67.6} & \multicolumn{2}{|c|}{76.9} & \multicolumn{2}{|c|}{$86 \cdot 7$} \\
\hline$\%$ Middle-Eastern & \multirow{2}{*}{\multicolumn{2}{|c|}{$\begin{array}{l}14 \cdot 7 \\
14.7\end{array}$}} & \multirow{2}{*}{\multicolumn{2}{|c|}{$\begin{array}{l}7.7 \\
7.7\end{array}$}} & \multicolumn{2}{|c|}{$6 \cdot 7$} \\
\hline$\%$ East Asian & & & & & 6 . & \\
\hline$\%$ Afro-Caribbean & \multicolumn{2}{|c|}{2.9} & \multicolumn{2}{|c|}{$7 \cdot 7$} & \multicolumn{2}{|c|}{0.0} \\
\hline
\end{tabular}

K-cit, potassium citrate.

Mean values were significantly different from those of the $\mathrm{KCl}$ group: ${ }^{*} P<0.05$. There were no significant differences at baseline (ANOVA or $\chi^{2}$ test) between the three groups other than stated.
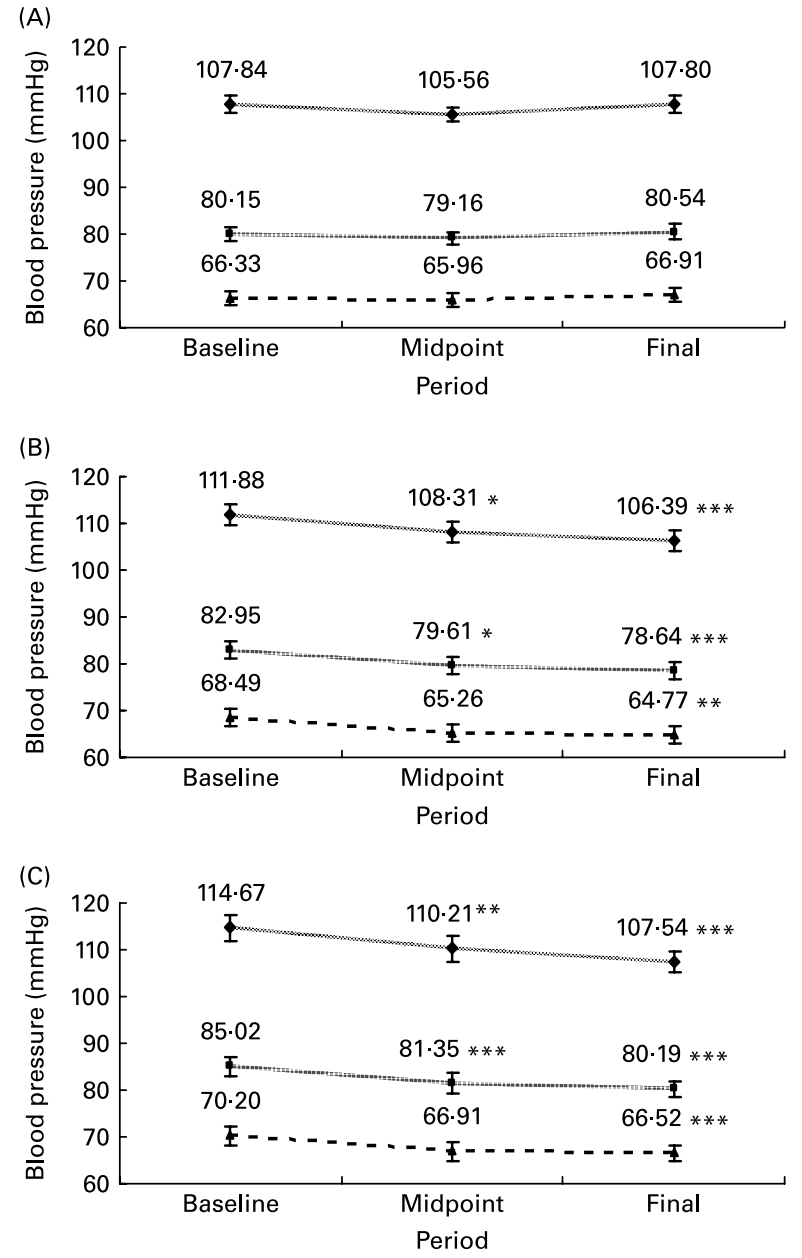

Fig. 2. Average blood pressure over the 6-week intervention period ( $\bullet$, systolic blood pressure; $\boldsymbol{\Lambda}$, diastolic blood pressure; $\mathbf{\square}, \mathrm{MAP}$, mean arterial pressure) for the three treatment groups (placebo, $\mathrm{A} ; \mathrm{KCl}, \mathrm{B}$; potassium citrate, C). Values are means with their standard errors depicted by vertical bars. Estimates for differences within each treatment group were assessed by the paired $t$ test, while between groups were assessed by ANOVA. Mean values were significantly different from baseline (within-group comparison): ${ }^{* *} P<0.05,{ }^{* *} P<0.01,{ }^{* * \star} P<0.005$. There were no significant differences within and between the three groups other than stated.

electrolytes within the three intervention groups. Changes in plasma electrolytes did not differ significantly between the different treatments.

There were no significant differences between the three groups in mean baseline values for erythrocyte potassium and water. Following treatment there were no significant changes between and within the groups in RBC-K (Table 3). After the intervention period erythrocyte water content decreased significantly in the placebo and K-cit group when compared with the respective baseline values but the changes were not significantly different between the three groups. Erythrocyte water content was found to be positively correlated with RBC-K ( $r 0.41, P=0.025)$ and plasma potassium $(r 0.59, P=0.000)$.

\section{$B M I$}

On completion of the study mean BMI had not changed significantly from baseline in any of the three treatments 
Table 2. Pairwise comparisons of changes in blood pressure between the potassium and placebo groups

(Mean values with their standard errors)

\begin{tabular}{|c|c|c|c|c|c|c|}
\hline & \multicolumn{6}{|c|}{ Change in blood pressure $(\mathrm{mmHg})$} \\
\hline & \multicolumn{3}{|c|}{ K-cit - placebo } & \multicolumn{3}{|c|}{$\mathrm{KCl}$ - placebo } \\
\hline & Mean & SEM & $95 \% \mathrm{Cl} \ddagger$ & Mean & SEM & $95 \% \mathrm{Cl}$ \\
\hline \multicolumn{7}{|c|}{ Midpoint from baseline§ } \\
\hline SBP & $-4.08^{*}$ & 1.43 & $-6.93,-1.23$ & $-3 \cdot 11^{*}$ & $1 \cdot 48$ & $-6.06,-0.16$ \\
\hline DBP & $-4 \cdot 17^{\star \star \star}$ & $1 \cdot 22$ & $-6 \cdot 61,-1 \cdot 73$ & $-3 \cdot 01^{\star \star \star}$ & $1 \cdot 27$ & $-5.53,-0.49$ \\
\hline MAP & $-4 \cdot 16^{\star \star \star}$ & 1.08 & $-6 \cdot 32,-2 \cdot 00$ & $-3 \cdot 06^{\star \star \star}$ & $1 \cdot 12$ & $-5.30,-0.83$ \\
\hline \multicolumn{7}{|c|}{ Final from baseline\| } \\
\hline SBPף & $-6 \cdot 69^{\star \star \star}$ & 1.09 & $-8 \cdot 85,-4.53$ & $-5 \cdot 24^{\star \star \star}$ & $1 \cdot 10$ & $-7.43,-3.06$ \\
\hline DBP & $-4 \cdot 26^{\star \star \star}$ & 1.03 & $-6 \cdot 31,-2 \cdot 21$ & $-4 \cdot 30^{\star \star \star}$ & 1.05 & $-6 \cdot 39,-2 \cdot 20$ \\
\hline MAP & $-5 \cdot 22^{\star \star \star}$ & 0.92 & $-7.04,-3.39$ & $-4 \cdot 70^{\star \star \star}$ & 0.94 & $-6 \cdot 56,-2 \cdot 84$ \\
\hline
\end{tabular}

DBP, diastolic blood pressure; K-cit, potassium citrate; MAP, mean arterial pressure; SBP, systolic blood pressure.

Mean values were significantly different from zero: ${ }^{\star} P<0 \cdot 05,{ }^{* \star \star} P<0.005$. Estimates for differences between groups were assessed by ANOVA with covariates (ANCOVA).

There were no significant differences between the three groups other than stated.

$\ddagger$ Derived from the least significant different test.

$\S$ Placebo $n 26, \mathrm{KCl} n 22, \mathrm{~K}$-cit $n 25$

\| Placebo $n 31, \mathrm{KCl} n 26$, K-cit $n 28$.

ๆ Changes are adjusted for SBP as covariate (SBP: $110.03, P=0.007)$.

groups (placebo: -0.11 (SEM 0.07) $\mathrm{kg} / \mathrm{m}^{2}, 95 \% \mathrm{CI}-0.25$, 0.04; KCl: -0.05 (SEM 0.08) kg/m², $95 \%$ CI $-0.21,0.11$; K-cit: 0.11 (SEM 0.08) kg/m², $95 \%$ CI $-0.04,0 \cdot 26$ ) nor was the mean change in BMI significantly different between the groups.

\section{Discussion}

In the present study we confirmed our earlier findings ${ }^{(14)}$ that an increase in dietary potassium of approximately $30 \mathrm{mmol} / \mathrm{d}$, equivalent to an increase in dietary potassium of around $40 \%$ in the UK population ${ }^{(23)}$ and to the amount contained in five portions of fresh fruits and vegetables, substantially decreases BP in predominantly young normotensive people. The effect was independent of the accompanying anion of the potassium salt, was greater in those with higher BP and increased with the duration of supplementation.

Pharmacological treatment is inappropriate for individuals who are not regarded as hypertensive, but have BP higher than the optimal level, and account for around 30-40\% of all BP-related $\mathrm{CVD}^{(1)}$. Of the non-pharmacological measures to manage $\mathrm{BP}$ weight control is considered to be one of the most effective ${ }^{(4)}$. The importance of body weight as a factor influencing BP is undisputed, and was appreciated in the current study, as a consistent positive correlation between BP and body weight or BMI was observed. The slight imbalance observed between the groups at baseline for BMI and height did not influence the BP-response to the supplements as in the current study BMI and height were used in the analysis of covariance without revealing a significance relationship with BP changes. Other lifestyle modifications have also been shown to influence BP independently of the changes in body weight ${ }^{(4)}$. A reduction of $50 \mathrm{mmol} / \mathrm{d}$ in salt intake bringing the total salt intake to an average $100 \mathrm{mmol} / \mathrm{d}^{(23)}$ is widely recommended ${ }^{(4)}$. However, this is acknowledged to be difficult to achieve and sustain, and would be of little benefit to normotensive individuals ${ }^{(24)}$. The fall in $\mathrm{BP}$ observed in the present and earlier study ${ }^{(14)}$ exceeded that which would result from removing $100 \mathrm{mmol} \mathrm{NaCl} / \mathrm{d}$ from the diet ${ }^{(25)}$ (equivalent to $62 \%$ of the customary salt intake in the $\mathrm{UK}^{(23)}$ ). A concomitant modest increase in potassium intake is an attractive possibility to complement a moderate salt restriction in order to reduce $\mathrm{BP}$, although likely to produce a result that is less than would be expected if the effects were additive $\mathrm{e}^{(5,7)}$. The major factor appears to be the molar ratio of sodium to potassium ${ }^{(5)}$.

There is a paucity of clinical trials exploring the effect of non-chloride salts on BP and of comparing the effect of different salts of potassium, but these have provided confusing results on the basis of the use of high dose levels of potassium, short duration ${ }^{(26)}$, small number of participants ${ }^{(27-29)}$ and lack of an appropriate control group ${ }^{(30)}$.

The present finding that a low-dose non-chloride potassium salt lowers BP has recently been supported in a study published after the completion of the current investigation. In this trial Franzoni et al. ${ }^{(31)}$ allocated 104 volunteers to receive either a $30 \mathrm{mmol} / \mathrm{d}$ potassium aspartate supplement or no treatment. After 4 weeks of intervention the authors observed a significant decrease in BP by $12 \cdot 2 / 8.2 \mathrm{mmHg}(P<0.001)$. The study, that was neither randomized nor placebo-controlled, indicated a greater effect than that observed in the current investigation. However, it was conducted on untreated hypertensive patients who are acknowledged to have a greater response to potassium ${ }^{(9,10)}$.

In contrast to the results of other authors ${ }^{(22,32)}$ we did not find any correlation between RBC-K and baseline BP levels nor did we observe an effect of supplementation on RBC-K. An explanation for the present result may partially arise from the fact that the sample of participants was relatively small and composed largely of young healthy normotensive subjects.

Whereas most of the potassium supplementation trials have been performed on hypertensive patients ${ }^{(9,10)}$, participants in the present study were predominantly normotensive, with a mean BP lower than the UK average of 126/71 (SBP/DBP) $\mathrm{mmHg}{ }^{(33)}$. Although not a representative sample of the UK population, our subjects had a sodium and potassium intake that was very similar to the average British consumption of 162 and $75 \mathrm{mmol} / \mathrm{d}$, respectively ${ }^{(23)}$. These facts together 
Table 3. Changes (final from baseline) in urinary electrolyte and creatinine, haematocrit, erythrocyte water and potassium content by treatment group (Mean values with their standard errors)

\begin{tabular}{|c|c|c|c|c|c|c|}
\hline & \multicolumn{2}{|c|}{ Placebo } & \multicolumn{2}{|c|}{$\mathrm{KCl}$} & \multicolumn{2}{|c|}{ Potassium citrate } \\
\hline & Mean & SEM & Mean & SEM & Mean & SEM \\
\hline Urinary creatinine $(\mathrm{mmol} / \mathrm{d})$ & $n 27$ & & $n 23$ & & $n 28$ & \\
\hline Baseline & 11.57 & 0.86 & 11.62 & 1.06 & 13.73 & 1.09 \\
\hline Change & -0.85 & 0.84 & -0.25 & 0.92 & $-2 \cdot 25^{\star \star}$ & 0.83 \\
\hline $95 \% \mathrm{Cl}$ & $-2.53,0.84$ & & $-2.08,1.57$ & & $-3.90,-0.60$ & \\
\hline Urinary K (mmol/d) & $n 27$ & & $n 23$ & & $n 28$ & \\
\hline Baseline & 71.68 & $5 \cdot 16$ & 71.91 & 6.57 & $78 \cdot 12$ & $5 \cdot 66$ \\
\hline Change & -4.93 & 6.04 & $17 \cdot 67^{\star} \dagger \dagger$ & 6.54 & $20.05^{\star \star}+\dagger$ & 5.93 \\
\hline $95 \% \mathrm{Cl}$ & $-16 \cdot 97,7 \cdot 10$ & & $4 \cdot 63,30 \cdot 71$ & & $8 \cdot 23,31 \cdot 86$ & \\
\hline Urinary $\mathrm{Na}(\mathrm{mmol} / \mathrm{d})$ & $n 27$ & & n 23 & & n 28 & \\
\hline Baseline & $128 \cdot 86$ & 12.54 & $132 \cdot 87$ & 14.73 & 153.49 & 14.03 \\
\hline Change & -8.79 & 13.37 & -9.95 & 14.50 & 0.01 & $13 \cdot 13$ \\
\hline $95 \% \mathrm{Cl}$ & $-35.43,17.84$ & & $-38.81,18.91$ & & $-26 \cdot 15,26 \cdot 17$ & \\
\hline $\mathrm{Na}-\mathrm{K}$ ratio & $n 27$ & & $n 23$ & & $n 28$ & \\
\hline Baseline & 1.94 & 0.22 & 2.04 & 0.21 & $2 \cdot 17$ & 0.19 \\
\hline Change & -0.01 & 0.24 & -0.49 & 0.26 & $-0.51^{*}$ & 0.23 \\
\hline $95 \% \mathrm{Cl}$ & $-0.48,0.46$ & & $-1.00,0.02$ & & $-0.97,-0.05$ & \\
\hline Plasma K (mmol/l) & $n 21$ & & $n 15$ & & n24 & \\
\hline Baseline & 4.26 & 0.07 & 4.27 & 0.11 & 4.36 & 0.12 \\
\hline Change & -0.01 & 0.12 & 0.03 & 0.14 & -0.20 & 0.11 \\
\hline $95 \% \mathrm{Cl}$ & $-0.26,0.23$ & & $-0.26,0.32$ & & $-0.43,0.02$ & \\
\hline Plasma $\mathrm{Na}(\mathrm{mmol} / \mathrm{l})$ & $n 21$ & & $n 15$ & & $n 24$ & \\
\hline Baseline & $140 \cdot 20$ & 0.30 & $139 \cdot 76$ & 0.52 & $140 \cdot 35$ & 0.26 \\
\hline Change & -0.23 & 0.40 & -0.08 & 0.47 & -0.80 & 0.37 \\
\hline $95 \% \mathrm{Cl}$ & $-1.02,0.57$ & & $-1.02,0.86$ & & $-1.54,-0.05$ & \\
\hline Haematocrit (\%) & $n 20$ & & $n 15$ & & $n 24$ & \\
\hline Baseline & 42.91 & 0.59 & 41.71 & 0.81 & $42 \cdot 60$ & 0.68 \\
\hline Change & -0.28 & 0.48 & 0.99 & 0.56 & -0.01 & 0.44 \\
\hline $95 \% \mathrm{Cl}$ & $-1.25,0.69$ & & $-0.13,2.11$ & & $-0.89,0.87$ & \\
\hline Erythrocyte water (\%) & $n 20$ & & $n 15$ & & $n 24$ & \\
\hline Baseline & 70.53 & 1.77 & 70.85 & $2 \cdot 13$ & 71.33 & 2.34 \\
\hline Change & $-0.99^{\star \star}$ & 0.61 & $-2 \cdot 27$ & 0.70 & $-1 \cdot 78^{\star \star}$ & 0.56 \\
\hline $95 \% \mathrm{Cl}$ & $-2.21,-0.23$ & & $-1.68,1 \cdot 13$ & & $-2.89,-0.67$ & \\
\hline RBC-K (mmol/kg dry wt) & $n 19$ & & $n 14$ & & $n 24$ & \\
\hline Baseline & $269 \cdot 80$ & 1.97 & 270.04 & 3.72 & $270 \cdot 66$ & 2.89 \\
\hline Change & -3.14 & 3.54 & 0.29 & $4 \cdot 12$ & -5.73 & $3 \cdot 15$ \\
\hline $95 \% \mathrm{Cl}$ & $-10.22,3.95$ & & $-7.97,8.54$ & & $-12.04,0.58$ & \\
\hline
\end{tabular}

$\mathrm{Na}-\mathrm{K}$ ratio, molar ratio of sodium to potassium; RBC-K, erythrocyte potassium content.

Mean values were significantly different from zero (within-group comparison): ${ }^{\star} P<0.05,{ }^{\star \star} P<0.01$. Estimates for differences within each treatment group were assessed by the paired $t$ test. There were no significant differences other than stated.

Mean values were significantly different from those of the placebo (between-groups comparison): $\dagger \dagger P<0.01$. Estimates for differences between groups were assessed by ANOVA for differences in baseline values and the ANOVA with covariates (ANCOVA) for effect of treatment. There were no significant differences other than stated.

‡Derived from ANCOVA.

would indicate that a modest increase in potassium intake, slightly exceeding the current recommendation, could make a substantial contribution to the prevention and prevalence of high BP in the UK adult population. Since BP shows a continuous relationship with the risk of CVD throughout its entire range, a small decrease in BP in the general population may lead to an appreciable decrease in mortality and morbidity ${ }^{(1,2)}$. It is predicted that a reduction in $\mathrm{BP}$ of the magnitude observed in the present study would decrease the mortality from all forms of CVD by approximately $15 \%{ }^{(2)}$.

As a means of increasing dietary potassium intake, raising the consumption of fresh fruits and vegetables is an obvious measure $^{(4)}$, although it may also prove difficult. As observed in the UK, despite the incessant and persuasive '5 a day' campaign $^{(34)}$ there has been little improvement in fruit and vegetable intake ${ }^{(35)}$. The average UK consumption is below three portions per day and around two portions in those in the lowest income group ${ }^{(36)}$.
Thus lifestyle changes might be implemented by diet modifications that do not depend on individual choice ${ }^{(1)}$. Substituting common salt with a mixture of $\mathrm{KCl}$ and $\mathrm{NaCl}$ has been shown to lower BP in hypertensive patients ${ }^{(37,38)}$ and to decrease the risk of $\mathrm{CVD}^{(39)}$. Currently a reduction in the salt content of manufactured foods is strongly recommended $^{(1,35)}$, as most dietary salt is derived from processed foods and little from discretionary use ${ }^{(2)}$. However, little is known about whether a substantial reduction in the salt content of manufactured foods might raise the use of discretionary salt. Other adjustments are also required, and restoration of potassium in food products would be a pragmatic approach.

\section{Acknowledgements}

The authors are grateful to Peter Milligan (Senior Application Advisor in Statistics, Computing and IT Services, King's 
College London) for advice on statistical procedures, to Professor Ramasamyiyer Swaminathan (Department of Chemical Pathology, St Thomas' Hospital London) for advice and collaboration in the analysis of the blood and urine samples. The study was partially funded by the Food and Drink Federation and by King's College Enterprises. A. B. was in receipt of a research scholarship from the King's College London Association. The authors declare that there is no conflict of interest.

\section{References}

1. Whelton PK (2004) Hypertension curriculum review: epidemiology and the prevention of hypertension. J Clin Hypertens (Greenwich) 6, 636-642.

2. Stamler J (1997) The INTERSALT Study: background, methods, findings, and implications. Am J Clin Nutr 65, Suppl. 2, $626 \mathrm{~S}-642 \mathrm{~S}$

3. Whitworth JA (2003) 2003 World Health Organization (WHO)/ International Society of Hypertension (ISH) statement on management of hypertension. J Hypertens 21, 1983-1992.

4. Appel LJ, Brands MW, Daniels SR, Karanja N, Elmer PJ \& Sacks FM (2006) Dietary approaches to prevent and treat hypertension: a scientific statement from the American Heart Association. Hypertension 47, 296-308.

5. Morris RC Jr, Schmidlin O, Frassetto LA \& Sebastian A (2006) Relationship and interaction between sodium and potassium. J Am Coll Nutr 25, Suppl. 3, 262S-270S.

6. Berkow SE \& Barnard ND (2005) Blood pressure regulation and vegetarian diets. Nutr Rev 63, 1-8.

7. Sacks FM, Svetkey LP, Vollmer WM, et al. (2001) Effects on blood pressure of reduced dietary sodium and the Dietary Approaches to Stop Hypertension (DASH) diet. DASHSodium Collaborative Research Group. $N$ Engl J Med 344, $3-10$.

8. Siani A, Strazzullo P, Giacco A, Pacioni D, Celentano E \& Mancini M (1991) Increasing the dietary potassium intake reduces the need for antihypertensive medication. Ann Intern Med 115, 753-759.

9. Whelton PK, He J, Cutler JA, Brancati FL, Appel LJ, Follmann D \& Klag MJ (1997) Effects of oral potassium on blood pressure. Meta-analysis of randomized controlled clinical trials. JAMA 277, 1624-1632.

10. Geleijnse JM, Kok FJ \& Grobbee DE (2003) Blood pressure response to changes in sodium and potassium intake: a metaregression analysis of randomised trials. J Hum Hypertens 17, 471-480.

11. Kotchen TA \& Kotchen JM (1997) Dietary sodium and blood pressure: interactions with other nutrients. Am J Clin Nutr 65, Suppl. 2, 708S-711S.

12. Demigne C, Sabboh H, Remesy C \& Meneton P (2004) Protective effects of high dietary potassium: nutritional and metabolic aspects. J Nutr 134, 2903-2906.

13. Schmidlin O, Forman A, Tanaka M, Sebastian A \& Morris RC Jr (1999) NaCl-induced renal vasoconstriction in salt-sensitive African Americans: antipressor and hemodynamic effects of potassium bicarbonate. Hypertension 33, 633-639.

14. Naismith DJ \& Braschi A (2003) The effect of low-dose potassium supplementation on blood pressure in apparently healthy volunteers. Br J Nutr 90, 53-60.

15. Beevers G, Lip GY \& O'Brien E (2001) ABC of hypertension. Blood pressure measurement. Part I - sphygmomanometry: factors common to all techniques. Br Med J 322, 981-985.

16. Beevers G, Lip GY \& O'Brien E (2001) ABC of hypertension. Blood pressure measurement. Part II - conventional sphygmo- manometry: technique of auscultatory blood pressure measurement. Br Med J 322, 1043-1047.

17. Longo D, Bertolo O, Toffanin G, Frezza P \& Palatini P (2002) Validation of the A\&D UA-631 (UA-779 Life Source) device for self-measurement of blood pressure and relationship between its performance and large artery compliance. Blood Press Monit 7, 243-248.

18. O'Brien E, Waeber B, Parati G, Staessen J \& Myers MG (2001) Blood pressure measuring devices: recommendations of the European Society of Hypertension. Br Med J 322, 531-536.

19. European Society of Hypertension - European Society of Cardiology (2003) Guidelines for the management of arterial hypertension. J Hypertens 21, 1011-1053.

20. O'Brien E, Beevers G \& Lip GY (2001) ABC of hypertension. Blood pressure measurement. Part IV - automated sphygmomanometry: self blood pressure measurement. $\mathrm{Br}$ Med $\mathrm{J}$ 322, $1167-1170$

21. Weissberg PL, West MJ \& Woods KL (1983) An improved method for measuring intracellular electrolytes in erythrocytes and the effects of cold storage. Clin Chim Acta 129, 85-89.

22. Delgado MC \& Delgado-Almeida A (2002) Red blood cell potassium and blood pressure in adolescents: a mixture analysis. Nutr Metab Cardiovasc Dis 12, 112-116.

23. Henderson LIK, Gregory J, Bates CJ, Prentice A, Perks J, Swan G \& Farron M on behalf of the Food Standards Agency and the Department of Health (2003) The National Diet \& Nutrition Survey: Adults Aged 19 to 64 Years. Vitamins and Mineral Intake and Urinary Analytes. Ministry of Agriculture, Fisheries and Food, National Statistics. London: Her Majesty's Stationary Office.

24. Hooper L, Bartlett C, Davey Smith G \& Ebrahim S (2002) Systematic review of long term effects of advice to reduce dietary salt in adults. $\mathrm{Br}$ Med $J \mathbf{3 2 5}, 628$.

25. He FJ \& MacGregor GA (2003) How far should salt intake be reduced? Hypertension 42, 1093-1099.

26. Mullen JT \& O'Connor DT (1990) Potassium effects on blood pressure: is the conjugate anion important? J Hum Hypertens 4, 589-596.

27. Overlack A, Stumpe KO, Moch B, Ollig A, Kleinmann R, Muller HM, Kolloch R \& Kruck F (1985) Hemodynamic, renal, and hormonal responses to changes in dietary potassium in normotensive and hypertensive man: long-term antihypertensive effect of potassium supplementation in essential hypertension. Klin Wochenschr 63, 352-360.

28. Overlack A, Conrad H \& Stumpe KO (1991) The influence of oral potassium citrate/bicarbonate on blood pressure in essential hypertension during unrestricted salt intake. Klin Wochenschr 69, Suppl. 2, 79-83.

29. Overlack A, Maus B, Ruppert M, Lennarz M, Kolloch R \& Stumpe KO (1995) Potassium citrate versus potassium chloride in essential hypertension. Effects on hemodynamic, hormonal and metabolic parameters. Dtsch Med Wochenschr 120, 631-635.

30. He FJ, Markandu ND, Coltart R, Barron J \& MacGregor GA (2005) Effect of short-term supplementation of potassium chloride and potassium citrate on blood pressure in hypertensives. Hypertension 45, 571-574.

31. Franzoni F, Santoro G, Carpi A, Da Prato F, Bartolomucci F, Femia FR, Prattichizzo F \& Galetta F (2005) Antihypertensive effect of oral potassium aspartate supplementation in mild to moderate arterial hypertension. Biomed Pharmacother 59, 25-29.

32. Resnick LM, Barbagallo M, Dominguez LJ, Veniero JM, Nicholson JP \& Gupta RK (2001) Relation of cellular potassium to other mineral ions in hypertension and diabetes. Hypertension 38, 709-712.

33. Ruston DHJ, Henderson L, Gregory J, Bates JC, Prentice A, Birch M, Swan G \& Farron M on behalf of the Food Standards 
Agency and the Department of Health (2004) The National Diet \& Nutrition Survey: Adults Aged 19 to 64 Years. Nutritional Status (Anthropometry and Blood Analytes), Blood Pressure and Physical Activity. Ministry of Agriculture, Fisheries and Food, National Statistics. London: Her Majesty's Stationary Office.

34. Attree P (2006) A critical analysis of UK public health policies in relation to diet and nutrition in low-income households. Matern Child Nutr 2, 67-78.

35. Kelly CN \& Stanner SA (2003) Diet and cardiovascular disease in the UK: are the messages getting across? Proc Nutr Soc 62, $583-589$.

36. Nelson M, Erens B, Bates B, Church $\mathrm{S} \&$ Boshier $\mathrm{T}$ on behalf of the Food Standards Agency (2007) Low Income Diet and
Nutrition Survey. Food Consumption. Nutrient Intake. London: Stationery Office.

37. Katz A, Rosenthal T, Maoz C, Peleg E, Zeidenstein R \& Levi Y (1999) Effect of a mineral salt diet on 24-h blood pressure monitoring in elderly hypertensive patients. J Hum Hypertens 13, 777-780

38. Geleijnse JM, Witteman JC, Bak AA, den Breeijen JH \& Grobbee DE (1994) Reduction in blood pressure with a low sodium, high potassium, high magnesium salt in older subjects with mild to moderate hypertension. Br Med J 309, 436-440.

39. Chang HY, Hu YW, Yue CS, Wen YW, Yeh WT, Hsu LS, Tsai SY \& Pan WH (2006) Effect of potassium-enriched salt on cardiovascular mortality and medical expenses of elderly men. Am J Clin Nutr 83, 1289-1296. 